\title{
СОЦИОЛОГИЯ РЕЛИГИИ
}

DOI 10.19181/nko.2021.27.3.3

УДК 316.7

\section{Н. Йованович Айзенхаммер ${ }^{1}$ \\ ${ }^{1}$ Белградский университет. Белград, Сербия.}

\section{УМЕРЕННО-ОРИЕНТАЛЬНОЕ ПРОЧТЕНИЕ (РЕЦЕПЦИЯ) ИСЛАМА В РАБОТАХ МАКСА ВЕБЕРА}

Аннотация. Данная работа посвещена видению Максом Вебером ислама как религии, которая породила воинов на Аравийском полуострове в VII веке, а также, в качестве логического продолжения, анализу данной интерпретации посредством теоретического подхода Эдварда Саида, то есть посредством теоретического ориентального подхода. В первой части работы представлены аспекты анализа ислама по Веберу, которые необходимо принимать во внимание, особенно в контексте компаративной теологии, то есть в свете рассмотрения особенностей ислама на фоне других мировых религий. Во второй части работы рассмотрена концепция ориентализма Саида и дан собственный апробированный теоретический подход в рамках умеренного ориентализма, который, по мнению авторов, является важным концептуальным коррективом, который может способствовать лучшему пониманию и анализу различных ориентальных дискурсов, в том числе и дискурса Вебера. Принимая во внимание то, что речь идет о возможно самом влиятельном классике социологии, в случае социологии религии, очень важно критически подойти к анализу его понимания ислама для того, чтобы мы определили, какие из его выводов значимы для социологии религии и социологии ислама и сегодня, а какие из его гипотез мы можем отнести к некому виду редукционизма или ориентализма.

Ключевые слова: Макс Вебер, ислам, ориентализм, военный ethos, социология религии.

Для цитирования: Йованович Айзенхаммер Н. Умеренно-ориентальное прочтение (рецепция) ислама в работах Макса Вебера // Наука. Культура. Общество. 2021. Том 27, № 3. С. 26-34. DOI: $10.19181 /$ nko.2021.27.3.3

Введение. Несмотря на то, что Макс Вебер является классиком социологии, чью теологическую теорию детально изучают уже десятилетиями, его анализ ислама в мировой социологии во многом оставлен без внимания. Гипотеза о связи между протестантской этикой и духом капитализма и в наше время вдохновляет социологов для дальнейших исследований, как и анализ христианства и его роли по Веберу в отрезвлении мира; как и анализ иудаизма, буддизма, индуизма, даосизма и конфуцианства, которые являются частой темой монографий и периодики, посвященной социологии религии. Однако, когда речь идет об исламе, имеет место иная ситуация. За исключением нескольких исследований, то есть отдельных авторов, которые занялись изучением данной проблемы [1-9], социология ислама по Веберу остается на периферии современных социологических работ. Одной из причин такого положения вещей в мировом академическом сообществе, вероятно, является тот факт, что Вебер не завершил собственную научную работу по исламу, хотя и собирался это сделать $[7$, р. 130; 8, p. 196; 9, p. 327] ${ }^{2}$. Другими словами, его размышления об исламе необходимо вниматель-

1 Статья основана на идеях диссертационного исследования «Понимание Вебером военного ethosa для становления и развития ислама» (автор Н. Йованович Айзенхаммер), защищенного на Философском факультете Белградского университета 22.05.2019 г.

2 Исследования протестантства, иудаизма, индуизма, буддизма, конфуцианства и даосизма имеют завершенный характер [10-13], поэтому и анализ этих религий имеет намного более глубокий (и подходящий для дальнейшего изучения) характер, чем его анализ ислама. 
но реконструировать, прежде всего, посредством анализа различных произведений, в которых он упоминает эту религию, что помимо всего прочего значит, что нужно очень осторожно делать окончательные выводы в связи с тем, в рамках какого подхода он понимает самую молодую монотеистическую религию. С другой стороны, облегчающим обстоятельством является согласованность описаний ислама в различных рукописях. За исключением суфизма, Вебер понимает ислам единообразно - как религию воинов. У него есть ясная гипотеза по поводу ислама, и он выдвигает её почти каждый раз, когда упоминает эту религию, основная идея её заключается в том, что целью пророка Мухаммеда было формирование нового государства, поэтому ислам должен был быть политической религией, чьей общественной базой были воины.

В данной работе, после краткого обзора аргументации Вебера по вопросу ислама как религии, которая ориентирована на военный этнос, авторы обосновывают важность рассмотрения его теории в ключе ориентализма, то есть в контексте теоретического подхода, который является наследием Эдварда Саида. В любом случае, теория Саида, также как и теория Вебера, будет рассмотрена критически, для получения наиболее объективного видения предмета исследования, состоящего в понимании Вебером ислама как религии a priori ориентированной на войну и борьбу.

(Редукционистское) Понимание Вебером ислама как религии воинов. Одна из основных гипотез Вебера заключается в том, что религиозные верования, практики, этику, мифологию и эстетику нельзя рассматривать как феномен per se, то есть нельзя пренебрегать социальным контекстом их возникновения и формирования. Вебер считает, что в «корне» каждой религиозной догмы лежат социальные и политические потребности некого общественного слоя, который в определенный исторический момент был носителем конкретного религиозного ethosa. Конечно, это не значит, что только один общественный слой участвует в формировании конкретной религиозной этики, но Вебер считает, что возможно идентифицировать доминантных классовых носителей замкнутой религиозной системы. Основывая теоретическую архитектонику на подобных эпистемологических принципах, Вебер своим религиоведческим исследованиям придал ингерентный и аутохтонный характер сощиологического, чем во многом дал импульс развитию дисциплины, которая в рамках социологии будет заниматься религиозными феноменами. В этой связи важно проанализировать то, каким образом Вебер связывает ислам с социальной стратой военных на Аравийском полуострове в VII веке.

Вебер считает, что крестьяне, рабы и подёнщики никогда не были носителями ни одного религиозного ethosa [14, p. 395], что интеллектуалы породили буддизм, а бюрократия - конфуцианство [14, p. 425], в то время как непривилегированные классы, такие как мещане и мелкие торговцы, стали плодородной почвой для возникновения христианства [14, р. 398]. Иудаизм представляет собой духовное отражение коллективной ненависти (ressentiment) народа-пария, который веками подвергался гонениям [12, p. 43; 14, p. 416-418], а ислам, по мнению Вебера, возник как религиозное «обеспечение» формирования нового государства, во главе которого будет духовный и светский вождь Пророк Мухаммед. Несмотря на то, что, как мы уже сказали, рассуждениям Вебера об исламе присущ сложный характер, данный вывод, который повторяется во многих его работах, весьма согласован и последователен. Исламское государство в контексте постоянной племенной вражды, повсеместно распространённого многобожия и заси- 
лья олигархии из Мекки не могло быть построено и укреплено никак иначе как в борьбе, поэтому военный императив в исламе является логическим догматическим выводом, считает Вебер. Он также указывает на то, что все другие элементы, которые, по его мнению, имеют место в этой религии (аффирмации рабства, мизогиния, андроцентризм и скромность этических целей), только сопутствуют реализации данной общей политической цели создания государства [15, p. 241].

В данном контексте, по словам Макса Вебера, необходимо рассматривать и императив существования священной религиозной войны в исламе. Когда Мухаммед перебрался из Мекки в Медину, то есть, когда он понял, что не сможет так легко навязать себя еврейским и другим племенам как неприкосновенного пророка, битвы, которые он вёл против неприятелей, он назвал священной войной. Таким образом, как полагает немецкий классик, началась кристаллизация идеи перехода мучеников пострадавших в священной войне против неверных в джаннат. «На основании этого Мухаммед развил нарратив священной войны вплоть до подчинения неверных политической власти и экономическому доминированию правоверных» [14, p. 400].

Вебер считает, что ислам - это религия, которая не отрицает реальный мир и своим воинам, павшим в священной войне, предлагает весьма привлекательные (земные) блага, которые они смогут наслаждаться. «Данная концепция предполагает эксклюзивность одного общего бога и моральное уродство неверных как его неприятелей, чьё беззаботное существование вызывает его праведный гнев. Поэтому этой концепции не было ни в античное время на Западе, ни в какой-либо азиатской стране во времена Заратустры; но тут и не было прямой связи между борьбой с неверием с одной, и религиозными чувствами с другой стороны. Истинным создателем этой связи является ислам» [14, p. 400].

Вебер, таким образом, ислам рассматривает как весьма гомогенную богословско-правовую систему, чью форму целиком определяют военные и государственные нужды новой мединской элиты. Как таковой, ислам предопределен быть ценностным столпом феодального и традиционно-патриархального государства и потому не может быть движущей силой ни для развития современного капитализма, ни для развития бюрократии и политического эквивалента современного капитализма - парламентарной демократии. Несмотря на присутствия дилеммы о том, рассматривал ли Вебер ислам как религию спасения или же все таки определял её как политическую религию stricto sensu (детальнее см.: [16]) ${ }^{3}$, сейчас мы оставим этот вопрос за пределами нашего исследования, и сосредоточимся на нескольких проблемах в связи с подобным пониманием ислама, которые в продолжение нашей работы послужат прологом к анализу понимания Вебером самой молодой монотеистической религии в ключе ориентализма.

Первая проблема, которая проистекает из понимания Вебером ислама - это его монолитный, то есть гомогенный подход к исламской догме и практике. Вебер только суфизм ${ }^{4}$ рассматривал как традицию, которая несколько отличается

${ }^{3}$ Ключевым вопросом понимания всей религиоведческой теории Вебера, а также для понимания его рецепции ислама, является изучение степени, в которой процесс рационализации присутствует в системе конкретной религии. В рамках изучения того, как далеко зашел процесс рационализации в религии и его масштаба, также ставится вопрос путей спасения. Вебер в отдельных работах относит ислам к религиям спасения, а в других - называет ислам политической религией. Рамки нашего исследования не позволяют углубиться в этот весьма сложный вопрос, но отметим, что это еще одна фундаментальная тема в рамках социологии религии Вебера, без которой нельзя рассматривать его понимание ислама (детальнее см.: [16]).

4 Вебер не разграничивает суннитов, шиитов и хариджитов, а также не рассматривает разницы интерпретаций ханбалитской, маликитской, шафиитской и ханафитской богословско-правовых школ. 
от других ветвей ислама, однако он нигде не разграничивает суннитов и шиитов, а также не выделяет различий между богословско-правовыми школами внутри этих двух главных течений в исламе. Несмотря на то, что в то время в немецкой ориенталистике ученым были известны различные интерпретации в исламе (детальнее см.: [17]), Вебер игнорирует их в своих работах и таким образом делает невозможным детальный и всеобъемлющий анализ различного понимания используемых определений - таких как, например, мученичество, священная войны и т.д. И хотя, конечно, с точки зрения эксклюзивного монотеизма, вера в Аллаха и пророка Мухаммеда, признание Корана как священной религиозной книги и основы шариата, являются общими для всех мусульман начиная c VII века и до наших дней, различия в понимании некоторых сегментов догм являются предметом спора, как в среде специалистов по исламскому праву, так и среди ученых. Эти различия в интерпретации очень важны, когда речь идет о сознательно-объективном, точном и основательном изучении ислама.

Объем нашего исследования не позволяет коснуться всех проблем, возникающих при анализе Вебером ислама в ходе его «столкновения» с аргументами исторического, историографического, догматического, а также теоретического характера, поэтому мы лишь упомянем некоторые из них. Одно из основных замечаний, которые мы можем адресовать Веберу - это недооценка значения торгового ethosa в формировании и распространении исламской догмы и практики. Даже, если мы согласимся с тем, что Вебер был прав, обозначив особое значение военной темы для политического аспекта ислама, мы не должны пренебрегать важностью, которую имела торговля, как для формулирования религиозных правил в сфере организации экономики мусульманского сообщества, так и для экспансии ислама дальше от Мекки и Медины. Также, важно пересмотреть и тезис о том, что ислам - это религия сравнимая исключительно с феодальной экономикой, а также политическим режимом и, в конце концов, что возможно является самым важным, необходимо пересмотреть и понимание Вебером ислама как религии, в которой спасение достигается только посредством страдания в священной войне. Пренебрежение различиями малого и великого джихада [18-19], как и всей совокупностью праксиологических мероприятий, которые достигли своего апофеоза, можно назвать серьезным недостатком данного подхода к эсхатологии ислама. Например, в анализе стоит, прежде всего, начать с пяти столпов ислама (молитва, пост, паломничество, милостыня и свидетельство веры), чтобы сразу столкнуться со сложностью обрядов, которые наполнены исключительно религиозным значением и коннотацией и которые можно, в свою очередь, детально анализировать в целях получения адекватного социологического исследования ислама [20]. Ни один из вышеуказанных пяти столпов не соотносится с военной темой, которую Вебер ставит на первый план. Конечно, это только первый шаг в анализе, который должен быть намного лучше разработан и который должен охватывать различные - как исторические, так и догматические аспекты. В отличие от авторов, которые понимание Вебером ислама называют однозначно ошибочным [1; 4-8; 21], мы не считаем, что можно так легко «осудить» немецкого классика. Военная тема в любом случае является важным сегментом

Однако, он выделяет суфизм как специфическую вариацию в рамках исламской традиции. На самом деле, Вебер определяет суфизм как религию дервишей и приравнивает его к дальневосточным почти магическим, экстатическим и мистическим обрядам и верованиям (14, р. 452). Данную точку зрения можно критиковать с различных аспектов, но здесь важно отметить, что суфизм является единственной ветвью в исламе, которую Вебер интерпретирует в ином ключе. 
исламской истории и догмы, и Вебер совершенно справедливо отметил данный аспект. Военный ethos в исламе необходимо изучать в соответствии с основными эпистемологическими началами общественных наук, однако, уже из этого краткого экскурса ясно, что Вебер рассматривает ислам в достаточно упрощенном свете, пренебрегая многими другими весьма важными элементами этой религии. Дискуссию о том, является ли это редукционистское освещение ориентализмом или некой иной формой симплификации мы представим в продолжение работы.

Ориентализм как приемлемый теоретический подход в рамках анализа западного дискурса об исламе. Эдвард Саид в 70-е годы сформулировал теоретическую и идеологическую платформу в противовес расизму, ксенофобии, сексизму и другим схожим позициям, нацеленную на описание и объяснение упрощенного и стереотипного отношения Окцидента к Ориенту. Саид утверждал, что хотя и имеет место схожесть с вышеуказанными ориентациями, ориентализм определяет специфическое отношение Запада к Востоку, которое может заключать в себе и расизм, и мизогинию, но не может быть объяснено посредством редукции к этим компонентам. В соответствии с идеями Фуко, Саид полагал, что существует специфический дискурс, который обеспечивает приращение (академического) знания об Ориенте, с помощью которого поддерживаются стереотипы о восточных народах как о ленивых, воинственных, отсталых, примитивных, нецивилизованных, варварских, патриархальных, иррациональных и т.д. С другой стороны этого нарративного корпуса находятся бинарные оппозиции, которые Запад определяют как прогрессивный, цивилизованный, эгалитарный, демократический, рациональный и пр. Посредством такого стереотипного подхода Запад конструирует и деконструирует Ориент как в большей степени Иное, а приписываемыми ему эпитетами стремится подчеркнуть собственное превосходство. Саид считает, что политическим последствием такого взгляда на положение вещей является оправдание колонизации Ориента (детальнее см.: [22-23]).

Другими словами, Саид определяет ориентализм как «прежде всего, дискурс, который не находится ни в каких прямых, корреспондентных отношениях с политической силой в широком смысле, а скорее создается и существует в неравноценном обмене с различными видами сил и до известной меры формируется в обмене с политической силой (как в случае колониального или империального истеблишмента), силой интеллекта (как в случае доминантных наук, таких как лингвистика или анатомия или какой-либо из современных политических наук), силой культуры (как в случае с догмами или канонами вкуса, текстов, ценностей), моральной силой (на примере идей о том, что «мы» можем, а «они» не могут делать или понимать так как «мы» можем)» [23, р. 23]. Следуя аргументации Фуко об обусловленности дискурса, знания и силы, Саид утверждает, что начиная от просветительства и дальше в западных академических кругах развивается и распространяется ориентальный дискурс, который придает законность политическим действиям в виде колониального давления.

Несмотря на то, что полемика по поводу теоретических подходов ориентализма началась сразу после издания труда (в 1978 году), и Саид многократно подвергался критике, его оспариваемая инновационная теоретическая позиция стала неотъемлемой частью не только постколониальных исследований, но и современной социологии, политологии и культурологии. Критика Саида - начиная от идеологической до теоретической и эпистемологической - в определенной степени оправдана: Саид рассматривал ориентализм во многом слишком экстенсивно и инклюзивно, поэтому и романтические предрассудки, и расистские сте- 
реотипы объединил обобщающим понятием. Также он, пренебрегая немецким ориентализмом (фокусируясь на французском, британском и американском) и преувеличивая значение науки и культуры для принятия политических решений, гомогенизировал как Запад, так и Восток, не углубляясь во внутренние особенности данных геополитических образований и т.д. Мы согласны с большей частью вышеприведённой критики, но также считаем, что он создал необходимый теоретический корректив в форме выделения и составления карты специфического отношения Запада к Ориенту, которое действительно сильно отличается от расизма и ксенофобии, и которое сразу было подхвачено как в академических, так и в политических кругах в целях колонизации. Но, все же самым большим недостатком подхода Саид мы можем назвать отнесение стереотипов с различной коннотацией (романтической, то есть описательной) в одну группу, в связи с чем мы акцентировали нюансы ориентализма и приспособили его к различным ценностным позициям, которые влекут за собой значительно отличающиеся политические последствия, и даже последствия в сфере безопасности.

Мы создали ориентальный спектр, в рамках которого можем позиционировать различные ориентальные нарративы, чтобы в качестве следующего шага, с помощью анализа содержания и анализа дискурса оценить масштаб и импликации ${ }^{5}$. На одной стороне данного ориентального спектра находятся все те подходы к пониманию Ориента, в которых преобладают стереотипное отношение и упрощенное рассмотрение восточных сообществ с ярко выраженным негативным подтекстом, причём эти стереотипы создаются в целях узаконивания колониального давления и завоевания. На другой стороне спектра находятся апологетические интерпретации Ориента, которым также присуща необъективная, но аффирмированная (романтическая) перцепция этих культур. Эти полюса ориентального спектра мы можем назвать негативно обусловленным ориентализмом и апологетическим ориентализмом. Между двумя этими полюсами находится и золотая середина, то есть умеренный ориентализм, который мы можем охарактеризовать с помощью (по крайней мере) трех важных критериев. Первый критерий, на основе которого мы в конкретном анализе идентифицируем присутствие ориентализма, заключается в симплификации и гомогенизации подхода к исламу как к монолитной богословско-правовой системе. Другим составляющим элементом ориентализма, особенно негативно обусловленного и умеренного, является выделение стереотипного видения ислама как a priori милитаристической религии (так как речь идет о наиболее часто связываемом с исламом стереотипе), в то время как третий критерий - это отсутствие ярко выраженной или скрытой политической претензии на освоение ближневосточной части мира, то есть создание гомогенной среды для оправдания интервенции на Ориент. Таким образом, умеренный ориентализм - это позиция, которая подразумевает наличие упрощенного взгляда на Ориент, присутствие стереотипов и симплификации (с акцентом на воинственность приписываемую мусульманам), но и отсутствие ярко выраженного намерения использовать эту дискуссию в колониальных или каких-либо других эксплуататорских и интернациональных целях в этой части света [24, p. 271-272].

Различия между тремя ориентальным позициями субтильны и их непросто идентифицировать, но существует необходимость получения ориентализмом

5 Напомним, что еще одно из замечаний по поводу видения Саидом ориентализма относится к фокусированию на отдельных обществах, поэтому мы конструируем этот спектр с намерением применить его к западному видению мусульманских, а не ориентальных сообществ в целом, но это не значит, что он не может иметь более широкого экспланаторного применения. 
обоюдоострой критики. Несмотря на общую основу всего того, что производит стереотипы об Ориенте - намерения, идеологические коннотации и политические последствия тут значительно отличаются. Мы считаем, что романтические путевые заметки о красоте восточных женщин нельзя отнести к той же категории, что и извещения о так называемой нецивилизованности и воинственности людей на Востоке, который поэтому нужно покорить. Умеренно ориентальная позиция несколько более близка экстремальному полюсу негативного ориентализма, однако отсутствие политической коннотации данного дискурса - это то, что, прежде всего, отделяет умеренный ориентализм от негативно обусловленного. Конструирование ориентального спектра и различных уровней ориентализма помимо всего прочего важно в контексте анализа понимания ислама Вебером и «отнесения» немецкого классика социологии к ориентальному спектру.

Заключение. Немногочисленные авторы, занимающиеся изучением анализа ислама в работах Макса Вебера, почти без исключения, относят его к ряду ориенталистов по Саиду [1; 4-6]. И хотя сам Саид не занимался творчеством немецкого классика (он упоминал его только опосредованно), авторы, изучающие немецкую исламологию, считают, что в понимании Вебером ислама имеют место стереотипы и упрощение, то есть ориентальный подход к самой молодой монотеистической религии. Мы согласны с этим выводом и определённо относим Вебера к ориенталистам, но с поправкой, что речь идет об умеренном ориентализме. Как мы увидели, Вебер не делает различий между интерпретациями ислама, сводит ислам к религии, сфокусированной на войне, и не углубляется в анализ вариаций значений и понимания, что его определенно позволяет отнести к группе ориенталистов. Однако, анализ Вебером ислама не был реализован в целях оправдания какого бы то ни было давления по отношению к этой части света - он никогда не упоминал подобную акцию, также и Германия в тот период времени не могла считаться колониальной силой. Ergo, анализ Вебером ислама является умеренно ориентальным и, как таковой, он оставляет нам возможность взять из него то, что приемлемо для социологического исследования ислама (прежде всего, мы имеем виду ценность его анализа роли класса военных в формирование и расширение ислама), но с поправкой на то, что речь идет об ориентальном упрощении, которое лишает ясности холистическую картину, которую должно было бы иметь любое социологическое исследование ислама. Мы считаем, что тут прекрасно объясняется один из аспектов исламской догмы и практики, и что этот аспект никак нельзя не учитывать при социологическом анализе ислама, но мы также считаем, что тут недооценивается или даже полностью отрицается существование ряда других весьма важных основополагающих праксиологических и теологических элементов, которые, если взять их в рассмотрение, дают значительно отличную, более объективную и менее ориентальную картину по сравнению с том, что оставил нам Макс Вебер.

В данной работе представлены только основные рамки и направления этой, весьма сложной темы. Каждый из упомянутых аспектов требует более глубокого анализа, чтобы прийти к твердым выводам, поэтому мы все же вынесли несколько главных постулатов, которые, по нашему мнению, должны стать теоретической и эпистемологической основой для изучения понимания Вебером ислама в контексте ориентального наследия. Конечно, мы снова делаем акцент на том, что понимание Вебером ислама осталось в рудиментарной форме и без законченной книги, которая возможно открыла бы нам некое иное и более детальное видение ислама, поэтому всю критику и выводы в этой связи необходимо рассматривать с осторожностью. 


\section{References}

1. Turner, B. (1998) Max Weber Classic Monographs. Volume VII: Weber and Islam. London and NewYork : Routledge. 212 p.

2. Turner, B. (2010) Islam, capitalism and the Weber theses. The British Journal of Sociology. Vol. 61. No 1. P. 147-160. DOI: https://doi.org/10.1111/j.1468-4446.2009.01243.x.

3. Max Weber and Islam (1999) Ed. by T. Huff \& W. Schluchter. New Brunswick, N.J. : Transaction Publ.. P. 332.

4. Salvatore, A. (1996) Beyond Orientalism? Max Weber and the Displacements of 'Essentialism' in the Study of Islam. Arabica.Vol. 43. No 3. P. 457-485. DOI: https://doi. org $/ 10.1163 / 1570058962582723$.

5. Farris, S. (2010) An 'Ideal Type' Called Orientalism - Selective Affinities between Edward Said and Max Weber. Interventions: International Journal of Postcolonial Studies. Vol. 12. No 2. P. 265-284. DOI: https://doi.org/10.1080/1369801X.2010.489701.

6. Farris, S. (2013) Max Weber's Theory of Personality: Individuation, Politics and Orientalism in the Sociology of Religion. Leiden, Boston : Brill. 229 p. ISBN 978-1608464166.

7. Bashier, S. (2011) The Long Shadow of Max Weber: The Notion of Transcendence and the Spirit of Mystical Islam. Journal of Levantine Studies. No 1. P. 129-151.

8. Sukidi (2006) Max Weber's Remarks on Islam: The Protestant Ethic among Muslim Puritans. Islam and Christian-Muslim Relations. Vol. 17. No 2. P. 195-205. DOI: https://doi. org $/ 10.1080 / 09596410600604484$.

9. Tenbruck, F. (1980) The Problem of thematic unity in the works of Max Weber. British Journal of Sociology. Vol. 31. No 3. P. 316-351.

10. Veber, M. (2011) Protestantska etika $i$ duh kapitalizma. Novi Sad : Mediterran Publ. $226 \mathrm{~s}$.

11. Weber, M. (1951) The Religion of China: Confucianism and Taoism. Glencoe, Illinois : The Free Press. 308 p.

12. Weber, M. (1952) Ancient Judaism. Glencoe Illinois: The Free Press. 484 p.

13. Weber, M. (1958) The Religion of India, the Sociology of Hinduism and Buddhism. Glencoe, Illinois : The Free Press. 392 p.

14. Veber, M. (1976) Privreda i društvo, knj. 1-2. Beograd : Prosveta. $498 \mathrm{~s}$.

15. Veber, M. (2015) Sociologija religije - tipovi religijskih zajednica. Novi Sad : Mediterran Publ. 249 s. ISBN: 978-86-6391-028-7.

16. Schluchter, W. (1987) Weber's Sociology of Rationalism and Typology of Religious Rejections of the World. In: Lash, S., Whimster, S. Max Weber, Rationalityand Modernity. London and New York : Routledge. P. 92-118.

17. Becker, C. H. (1974) Christianity and Islam. New York: Burt Franklin Reprints.

18. Esposito, L. J. (2003) Unholy War: Terror in the Name of Islam. New York, Oksford : Oksford University Press. 196 p. ISBN 0-19-515435-5.

19. Cook, D. (2005) Understanding Jihad. Berkley, Los Angeles, London : University of California Press. 269 p.

20. Vukomanović, M. (2004) Religija. Beograd : Zavod za udžbenike i nastavna sredstva.

21. Rodinson, M. (1973) Islam and Capitalism. NewYork : Pantheon Books. 308 p. ISBN 978-0394467191.

22. Said, E. (2002) Kultura i imperijalizam. Beograd : Beogradski krug. 645 s.

23. Said, E. (2008) Orijentalizam. Beograd : Biblioteka XX vek. 480 s.

24. Jovanović, N. (2017) Contemporary Orientalistic discourse as the framework for the analysis of Islamophobia in Western societies. In: Stanarević S., Đorđević I., Rokvić V, (eds). 3 rd International Conference on Human Security, Belgrade, May 2017, University of Belgrade Faculty of Security Studies, Human Security Research Center. P. 272-274.

Дата поступления в редакцию: 01.09.2021.

Принята к печати: 16.09.2021.

\section{Сведения об авторе:}

Йованович Айзенхаммер Наташа, доктор социологических наук, доцент, кафедра социологии Философского факультета, Белградский университет. Белград, Сербия.

e-mail: natasa.jovanovic@f.bg.ac.rs

ORCID: 0000-0002-3151-9732 
N. Jovanovic Ajzenhamer ${ }^{1}$

${ }^{1}$ University of Belgrade. Belgrade, Serbia.

\title{
MODERN ORIENTAL READING (RECEPTION) OF ISLAM IN THE WORKS OF MAX WEBER
}

\begin{abstract}
In this paper we analyse Max Weber's view on Islam as a religion of warriors who lived at the Arabian Peninsula in the 7th century, and also, we analyse this interpretation in the context of Edward Said's (orientalistic) theoretical approach. The first part of the paper presents various aspects of the analysis of Islam by Max Weber, which must be taken into the context of comparative theology, that is, in the light of considering the characteristics of Islam against the background of other world religions. In the second part of the work, we will analyse the concept of Said's orientalism. We will construct the framework of moderate orientalism, which, according to the author of this paper, is an important conceptual adjustment that can contribute to a better understanding and analysis of various oriental discourses, including Weber discourse. Taking into account that we are talking about the most influential classics sociologists, especially in the case of the sociology of religion, it is very important to critically analyse his understanding of Islam so that we can determine which of his conclusions are significant for the sociology of religion and the sociology of Islam today, and which of his hypotheses can we attribute to some kind of reductionism or orientalism.
\end{abstract}

Keywords: Max Weber, Islam, Orientalism, military ethos, sociology of religion.

For citation: Jovanovic Ajzenhamer N. (2021) Modern oriental reading (reception) of Islam in the works of Max Weber. Science. Culture. Society. Vol. 27. № 3. P. 26-34. DOI: 10.19181/nko.2021.27.3.3

The article was submitted on September 01, 2021.

Accepted on September 16, 2021.

Information about the author:

Nataša Jovanović Ajzenhamer, PhD (sociology), Associate Professor, Department of Sociology, Faculty of Philosophy, University of Belgrade. Belgrade, Serbia. e-mail: natasa.jovanovic@f.bg.ac.rs

ORCID: 0000-0002-3151-9732 